\title{
Article \\ Dietary Quality, Sleep Quality and Muscle Mass Predicted Frailty among Chinese Postmenopausal Women in Malaysia
}

\author{
Kai Sze Chan ${ }^{1}$, Yoke Mun Chan ${ }^{1,2,3, *}$, Yit Siew Chin $^{4}\left(\mathbb{D}\right.$ and Zalilah Mohd Shariff ${ }^{4}(\mathbb{D}$ \\ 1 Department of Dietetics, Faculty of Medicine and Health Sciences, Universiti Putra Malaysia, \\ Seri Kembangan 43400, Selangor, Malaysia; kenszechan@gmail.com \\ 2 Research Center of Excellence, Nutrition and Non-Communicable Diseases, Universiti Putra Malaysia, \\ Seri Kembangan 43400, Selangor, Malaysia \\ 3 Malaysian Research Institute on Ageing, Universiti Putra Malaysia, \\ Seri Kembangan 43400, Selangor, Malaysia \\ 4 Department of Nutrition, Faculty of Medicine and Health Sciences, Universiti Putra Malaysia, \\ Seri Kembangan 43400, Selangor, Malaysia; chinys@upm.edu.my (Y.S.C.); zalilahms@upm.edu.my (Z.M.S.) \\ * Correspondence: cym@upm.edu.my; Tel.: +60-39769-2433
}

check for updates

Citation: Chan, K.S.; Chan, Y.M.; Chin, Y.S.; Mohd Shariff, Z. Dietary Quality, Sleep Quality and Muscle Mass Predicted Frailty among Chinese Postmenopausal Women in Malaysia. Int. J. Environ. Res. Public Health 2022, 19, 2565. https:// doi.org/10.3390/ijerph19052565

Academic Editor: Eusebio Chiefari

Received: 29 September 2021

Accepted: 29 November 2021

Published: 23 February 2022

Publisher's Note: MDPI stays neutral with regard to jurisdictional claims in published maps and institutional affiliations.

Copyright: (c) 2022 by the authors. Licensee MDPI, Basel, Switzerland. This article is an open access article distributed under the terms and conditions of the Creative Commons Attribution (CC BY) license (https:/ creativecommons.org/licenses/by/ $4.0 /)$

\begin{abstract}
The older adult population is growing faster than any age group, which increases their risk of frailty. Studies conducted among older adult are relatively scarce in Malaysia, especially among Chinese postmenopausal women, who have the longest life expectancy. Thus, the present study aimed to determine the prevalence of frailty and its associated factors among Chinese postmenopausal women. A total of 220 eligible respondents were recruited, with information on sociodemographic background, comorbidities, dietary intake and lifestyle behaviour were obtained using a structured questionnaire, while anthropometry indicators were assessed according to standard protocol. Fasting blood was withdrawn for the analysis of serum 25(OH)D. Multinomial logistic regression was used to determine factors that predict pre-frailty and frailty. Prevalence of pre-frailty and prevalence of frailty were 64.5 and $7.3 \%$, respectively, and most of the respondents presented with weak handgrip strength. Pre-frailty was prevalent among the younger population. Dietary quality was unsatisfactory among the respondents, and the majority of them presented with a high percentage of body fat. An increased dietary quality index (DQI), poor sleep and low muscle mass were factors that contributed to frailty. In conclusion, nutritional factors should be considered in developing health-related policies and programs in reducing and delaying the onset of frailty.
\end{abstract}

Keywords: frailty; Chinese postmenopausal women; dietary quality; skeletal muscle mass; sleeping quality

\section{Introduction}

Worldwide, there is an increase in life expectancy, representing one of the key drivers of population ageing in addition to decreased fertility. The pace of population ageing is increasing dramatically, with the elderly population expected to be doubled or tripled in the years 2050 and 2100, respectively [1]. Malaysia is not exempt from the ageing population scenario commonly observed in Asian countries. According to the Department of Statistics Malaysia, approximately 7\% of the total population was older people in 2019 [2], and this is expected to reach $14.5 \%$ in 2040 [3]. However, this increase in longevity often does not correspond with better functional abilities. Frailty, a recognised geriatric syndrome, is expected to increase with the substantial growth of the elderly population. The prevalence of frailty among the population aged 50 years old and above in 18 European countries was $7.7 \%$, with almost half of the population being pre-frail [4]. Across Asia, the highest prevalence of frailty was reported in Hong Kong and Beijing [5-7]. In Malaysia, the prevalence of frailty was $15.9 \%$ among the elderly population in a recent study [8]. Individuals with frailty had an increased risk of disability and mortality [9], which deteriorated their 
health and increased individual and nation medical expenditures [10]. In addition to increased risk of disability, individuals with frailty may also have an increased risk of cardiovascular disease-related morbidity and mortality [11], which signify the need for appropriate preventive measures.

To the best of knowledge, previous studies on frailty in Malaysia focused on the elderly population aged 60 years and above [8,12-15]. Contrary to popular belief, frailty is not limited to older people [16], and it is indeed an overlooked problem among the middle-aged population. Precursors of frailty tend to arise earlier in the life course, where the antecedents of frailty in late life could have manifested at middle age [16]. Frailty predicts future disability, but it is modifiable, particularly at an early stage [17], suggesting that identifying predictors for frailty and pre-frailty in younger populations might reduce the occurrence of frailty when they are older. Despite the importance of identifying the risk of frailty in middle-aged people, most epidemiological studies assessing frailty have excluded those younger than 65 years, and, as such, little is known about frailty in younger populations [17]. In the absence of appropriate intervention or health policies, the middleaged population, especially postmenopausal women, is expected to experience a steep increase in the risk of frailty when their age increases. Hence, the present study aimed to investigate the magnitude of frailty among middle-aged and older postmenopausal women and factors associated with frailty among these postmenopausal women in Malaysia.

\section{Materials and Methods}

\subsection{Study Design and Study Population}

This was a cross-sectional study, and a total of 220 community-dwelling postmenopausal Chinese women were recruited from affiliates of senior citizen organisation in Kuala Lumpur and Selangor, Malaysia. Ethical approval was granted (Ethics Committee for Research Involving Human Subjects of Universiti Putra Malaysia; reference number: JKEUPM-2018-056; approved on 31 May 2018), and permission to conduct this study was obtained from the respective affiliates before study enrolment. Eligibility of respondents was limited to women who had menopause naturally for at least five years, while those with medical diagnoses of severe diseases, such as cardiovascular diseases, cancer, stroke, Parkinson disease and impaired liver and renal function, were excluded. Written consent was obtained from the respondents before study commencement.

\subsection{Assessment of Frailty}

The presence of frailty among respondents was ascertained based on the most widely cited phenotype criteria [9], namely, unintentional weight loss, self-reported exhaustion, decreased handgrip strength, low gait speed and low energy expenditure. The presence of weight loss among the respondents was ascertained with the following question "In the last year, have you lost more than $4.5 \mathrm{~kg}$ unintentionally (i.e., not due to dieting or exercise)?" Respondents who answered "Yes" and did not report any ongoing weight loss programme were considered to have experienced unintentional weight loss. Exhaustion was assessed using the depression scale of the Centre for Epidemiological Studies (CES-D) [18], which comprises the following questions: "How often in the last week did you feel that everything you did was an effort?" and "How often in the last week did you feel that you could not get going?" Possible responses were on a four-point Likert Scale, which ranged from $0=$ rarely or none of the time ( $<1$ day), $1=$ some or a little of the time (1-2 days), $2=$ a moderate amount of the time ( $3-4$ days), to $3=$ most of the time. Respondents who chose " 2 " or " 3 " to any two questions were considered to self-report exhaustion. The handgrip strength of respondents was measured using a routinely calibrated dynamometer on their dominant hands, following a standard protocol. An average reading of handgrip strength was taken from two measurements and compared to the existing cut-off value [9], as stratified by the body mass index (BMI) of respondents.

On the other hand, time taken to complete a $4.5 \mathrm{~m}$ distance walk was used to determine the gait speed of the respondents. Respondents with a walking time equal to or 
more than the recommended cut-off value (for height $\leq 159 \mathrm{~cm}$, cut-off value $\geq 7 \mathrm{~s}$; for height $>159 \mathrm{~cm}$, cut-off value $\geq 6 \mathrm{~s}$ ) were considered to possess a slow gait speed. The level of physical activity of respondents was assessed with the Global Physical Activity Questionnaire (GPAQ) [19], which quantifies the physical activity level of respondents of various aspects, such as work, travel, recreation, and sedentary activities in the past seven days, with an energy expenditure of less than $270 \mathrm{kcal} /$ week considered as a low physical activity level. Respondents were classified as non-frail if they did not present with any of the five criteria; respondents presenting with one to two criteria were considered pre-frail, while respondents who fulfilled at least three criteria were considered frail.

\subsection{Sociodemographic Background}

Information on sociodemographic background, such as age, years of education, marital status and monthly household income, was obtained. The monthly household income (in Ringgit Malaysia (RM) $3.98=$ USD 1 at the time of data collection) was categorised into low (<RM 2300, or USD 588), medium (RM 2300-5599 or USD 588-1407) and high (>RM 5600 or USD 1407) based on the Malaysian Economic Planning Unit [20].

\subsection{Dietary Quality Index (DQI)}

All respondents were requested to recall their habitual food intake for the past month using a validated semi-quantitative food frequency questionnaire (sFFQ) adapted from the Malaysian Adult Nutrition Survey 2014 [21]. The sFFQ consists of 165 food items and is categorised into 13 food groups. The amount of food and beverages consumed by the respondents in household measures (bowls, cups, and plates) was converted into metric quantities (in gram) and analysed further using NutritionistPro ${ }^{\circledR}$ software (Axxya System, 2008). The dietary quality of respondents was assessed with the Healthy Eating Index for Malaysians (HEI-M), which was developed and validated among the Malaysian population [22]. The HEI-M consists of nine components, whereby the seven components, namely, cereal and grains, fruits, vegetables, meat, egg and poultry, fish, legumes and milk and dairy products, assessed the dietary adherence of respondents on the Malaysian Dietary Guidelines (MDG) 2010, while the other two components were reported in percentage of total fat consumption and sodium intake [23]. The score of each component ranges from 0 (lack of compliance) to 10 (full compliance), and the score was calculated proportionately for in-between responses. The overall DQI for the respondent was determined by adding up the scores, and a composite score was computed with the following formula: (total score of 9 components $/ 9 \times 10) \times 100 \%$. Scores from all components are summed up to yield the diet quality, ranging from 0 to 100, with a higher score indicating a good diet quality.

\subsection{Lifestyle Behaviour}

Sedentary behaviour and sleeping quality of respondents were assessed using the Global Physical Activity Questionnaire (GPAQ) [19] and the 19 self-rated Pittsburgh Sleep Quality Index (PSQI) questionnaires, respectively [24]. Permission to use the sleeping quality instrument was obtained before study commencement. Besides an individual's perception of sleep quality, respondents were assessed on the duration of sleep, habitual sleep efficiency, use of sleep medication, presence of sleep latency (defined as duration to fall asleep), sleep disturbances (defined as any reason that may affect the respondent's sleep) and daytime dysfunction to allow for the determination of sleep quality. Each component was weighted equally on a 3-point Likert scale, and a score of " 0 " indicated no difficulty, while a score of " 3 " indicated severe difficulty. The score from each component was summed to yield the sleeping quality index score, which can range from 0 (no difficulty) to 21 (severe difficulty in all areas) [24].

\subsection{Anthropometry Measurements}

Anthropometry measurements (weight, height and percentage of body fat (PBF)) of the respondents were performed using calibrated instruments. The body weight and 
height of respondents were assessed with TANITA Digital Weight Scale HD306 (TANITA Corporation, Arlington Heights, IL, USA) to the nearest $0.1 \mathrm{~kg}$ and SECA Stadiometer SE217 (SECA, Hamburg, Germany) to the nearest $0.1 \mathrm{~cm}$, respectively. The body mass index of respondents was computed as weight $/$ height $^{2}$ and categorised into four categories: underweight, normal, overweight and obese [25]. The body fat percentage was assessed with the OMRON body fat monitor HBF-306 (Omron Matsusaka Co. Ltd., Matsusaka, Japan) with up to $0.1 \%$ accuracy, while the skeletal muscle mass (SMM) of respondents was calculated based on the following formula: $\mathrm{SMM}(\mathrm{kg})=0.244 \times$ body weight $(\mathrm{kg})+$ $7.8 \times$ height $(\mathrm{m})-0.098 \times$ age $+6.6 \times$ sex $($ female $=0)+$ race $($ Asian $=-1.6)-3.3$ [26] . Presence of sarcopenia was confirmed according to criteria of the Asian Working Group for Sarcopenia (AWGS 2019), namely, respondents with SMM/square of height $\leq 5.7 \mathrm{~kg} / \mathrm{m}^{2}$ and either low gait speed (walking speed $<1.0 \mathrm{~m} / \mathrm{s}$ ) or low muscle strength (handgrip strength $<18 \mathrm{~kg}$ ) [27].

\subsection{Serum Vitamin $D$}

Fasting venous blood was drawn from participants on the morning after a minimum of $8 \mathrm{~h}$ of overnight fasting. The specimen was sent to a commercial lab for analysis. Serum vitamin D $(25(\mathrm{OH}) \mathrm{D})$ was measured using ADVIA Centaur Vitamin D Total assay with the analytical measuring range between 4.2 to $150 \mathrm{ng} / \mathrm{mL}$ (10.5 to $375 \mathrm{nmol} / \mathrm{L})$. Vitamin D status of respondents was classified into three subgroups according to the recommendation by the Institute of Medicine [28].

\subsection{Charlson Comorbidity Index}

The presence of comorbidity was self-reported by respondents, and the Charlson comorbidity index (CCI) was used to quantify the respondents' comorbid disease burden. The CCI assigned weight for each disease, and the total score was calculated by adding the weights [29]. The Charlson comorbidity index has been used extensively in the medical literature for comorbidity assessment, and it is universally used to predict short- and long-term mortality [30].

\subsection{Statistical Analysis}

The data were analysed using IBM SPSS Statistics 22.0 (SPSS Inc., Chicago, IL, USA). An independent-sample $t$-test was used to determine the mean differences between respondents who were non-frail and at risk of frailty. Pearson chi square $\left(\chi^{2}\right)$ was used to determine the associations between potential factors and risk of frailty. Multinomial logistic regression analysis was performed to determine the odds ratios of factors affecting the risk of frailty among respondents, whereby variables with significance level at $p<0.25$ at univariate logistic regression analysis were selected into the final model [31]. Binary logistic regression analysis was also performed to determine the odd ratios of factors affecting the diagnostic components of frailty among respondents. The statistical significance level was set at $p<0.05$.

\section{Results}

\subsection{Prevalence of Frailty and Distribution of Frailty Components}

Prevalence of pre-frailty and prevalence of frailty were 64.5 and $7.3 \%$, respectively (Table 1), with approximately three out of four respondents presented with at least one component of frailty. Slightly more than half of the respondents had weak handgrip strength, followed by another quarter with a low physical activity level. On the other hand, unintentional weight loss was not common, with less than $6 \%$ of the respondents self-reporting this issue. A significantly higher number of older respondents (aged 65 years old and above) were pre-frail and frail $\left(\chi^{2}=8.269, p<0.05\right)$, presented with more frailty components $\left(\chi^{2}=10.775, p<0.05\right)$ and had low grip strength $\left(\chi^{2}=4.398, p<0.05\right)$ and low gait speed $\left(\chi^{2}=6.241, p<0.05\right)$ as compared to their younger counterparts. On the other hand, despite only $2 \%$ being frail, more than $60 \%$ of the younger respondents were pre-frail. 
Table 1. Prevalence of frailty and its components of the respondents $(n=220)$.

\begin{tabular}{|c|c|c|c|c|}
\hline Characteristics & & $n(\%)$ & & $p$-Value \\
\hline Frailty phenotype & $<65$ years old & $\geq 65$ years old & Total & $0.016^{*}$ \\
\hline Non-frail & $32(35.2)$ & $30(23.3)$ & $62(28.2)$ & \\
\hline Pre-frail & $57(62.6)$ & $85(65.9)$ & $142(64.5)$ & \\
\hline Frail & $2(2.2)$ & $14(10.8)$ & $16(7.3)$ & \\
\hline $\begin{array}{l}\text { Number of frailty components } \\
\text { present }\end{array}$ & & & & $0.029 *$ \\
\hline 0 & $32(35.2)$ & $30(23.3)$ & $62(28.2)$ & \\
\hline 1 & $40(44.0)$ & $49(38.0)$ & $89(40.5)$ & \\
\hline 2 & $17(18.7)$ & $36(27.9)$ & $53(24.1)$ & \\
\hline 3 & $2(2.1)$ & $11(8.5)$ & $13(5.9)$ & \\
\hline 4 & $0(0.0)$ & $3(2.3)$ & $3(1.4)$ & \\
\hline 5 & $0(0.0)$ & $0(0.0)$ & $0(0.0)$ & \\
\hline \multicolumn{5}{|l|}{ Distribution of frailty components } \\
\hline Weak handgrip strength & $39(34.2)$ & $75(65.8)$ & $114(51.8)$ & $0.036^{*}$ \\
\hline Low physical activity level & $19(33.9)$ & $37(66.1)$ & $56(25.5)$ & 0.250 \\
\hline Self-reported exhaustion & $12(34.3)$ & $23(65.7)$ & $35(15.9)$ & 0.459 \\
\hline Slow gait speed & $5(17.9)$ & $23(82.1)$ & $28(12.7)$ & 0.012 * \\
\hline Unintentional weight loss & $5(38.5)$ & $8(61.5)$ & $13(5.9)$ & 1.000 \\
\hline
\end{tabular}

* Significant at $p<0.05$, two-tailed.

\subsection{Characteristics of Respondents}

Table 2 shows the distribution of respondents by frailty status as stratified by sociodemographic background, DQI, lifestyle factors, anthropometry indicators and $25(\mathrm{OH}) \mathrm{D}$ levels. The mean age of respondents was $66 \pm 7$ years, and the majority were married and had formal education, with a mean year of education of eight years. The respondents had either a low or a middle household income, while only approximately $20 \%$ had a high household income. Dietary quality among the respondents was unsatisfactory, with a mean DQI score slightly higher than 60 out of a possible score of 100. Approximately $87 \%$ of the respondents required an improved diet, with another $11 \%$ having poor dietary quality. More than half of the respondents were poor sleepers. In addition, despite only a quarter of the respondents being physically inactive (as shown in Table 1), the prevalence of sedentarism was high, with respondents displaying approximately four hours of sedentary behaviour daily.

Regarding anthropometric measurement, more than half of the respondents had a normal body weight but with a high PBF. The mean SMM of respondents was approximately $15 \mathrm{~kg}$, with approximately $20 \%$ of the female having low SMM, and $12 \%$ were sarcopenic. Overall, the mean $25(\mathrm{OH}) \mathrm{D}$ level was approximately $38 \mathrm{nmol} / \mathrm{L}$, with more than $80 \%$ of the respondents being either deficient or insufficient in vitamin $\mathrm{D}$.

As the total number of respondents with frailty was small, respondents with pre-frailty and frailty were combined into one group, re-labelled as at risk of frailty (characterised by respondents presenting with at least one component for diagnosing frailty). Approximately one out of three respondents aged less than 65 years old was at risk of frailty. Respondents at risk of frailty were significantly older $(\mathrm{t}=-2.100, p=0.037)$, had a longer duration of menopause $(\mathrm{t}=-2.809, p=0.006)$ and received fewer years of education $(\mathrm{t}=0.928$, $p=0.045$ ). Despite the means, SMM was comparable between non-frail and frail respondents. All non-frail respondents were not sarcopenic, while approximately one in five frail respondents was sarcopenic $\left(\chi^{2}=10.543, p=0.001\right)$. Likewise, the two groups had comparable characteristics. 
Table 2. Distribution of characteristics of respondents according to frailty status $(n=220)$.

\begin{tabular}{|c|c|c|c|c|}
\hline Characteristics & $\begin{array}{l}\text { Non-Frailty } \\
\quad(n=62)\end{array}$ & $\begin{array}{l}\text { Risk of Frailty } \\
\quad(n=158)\end{array}$ & Total & $p$-Value \\
\hline Age (year) & $64.98 \pm 5.65$ & $67.05 \pm 6.89$ & $66.47 \pm 6.62$ & $0.037^{* *}$ \\
\hline$<65$ years old & $32(51.6)$ & $59(37.3)$ & $91(41.4)$ & \multirow{2}{*}{0.075} \\
\hline$\geq 65$ years old & $30(48.4)$ & $99(62.7)$ & $129(58.6)$ & \\
\hline Duration of menopause (year) & $13.98 \pm 6.36$ & $16.89 \pm 8.13$ & $16.07 \pm 7.77$ & $0.006^{* *}$ \\
\hline \multicolumn{5}{|l|}{ Marital status } \\
\hline Single/divorced & $16(25.8)$ & $33(20.9)$ & $49(22.3)$ & \multirow{2}{*}{0.543} \\
\hline Married & $46(74.2)$ & $125(79.1)$ & $171(77.7)$ & \\
\hline Year of education (years) ${ }^{a}$ & $9.01 \pm 4.39$ & $7.62 \pm 4.66$ & $8.01 \pm 4.62$ & $0.045^{*}$ \\
\hline No formal education & $5(8.1)$ & $22(13.9)$ & $27(12.3)$ & \multirow{2}{*}{0.335} \\
\hline With formal education & 57 (91.9) & $136(86.1)$ & $193(87.7)$ & \\
\hline \multicolumn{5}{|l|}{ Monthly household income ${ }^{b}$} \\
\hline$<$ RM 2300 & $20(32.3)$ & $76(48.1)$ & $96(43.6)$ & \multirow{3}{*}{0.101} \\
\hline RM 2300-5599 & $27(43.5)$ & $54(37.2)$ & $81(36.8)$ & \\
\hline$\geq$ RM 5600 & $15(24.2)$ & $28(14.7)$ & $43(19.5)$ & \\
\hline DQI & $59.66 \pm 8.54$ & $61.68 \pm 9.24$ & $61.11 \pm 9.08$ & 0.139 \\
\hline Poor $(<50.00 \%)$ & $9(14.5)$ & $15(9.5)$ & $24(10.9)$ & \multirow{3}{*}{-} \\
\hline Needs improvement & $53(85.5)$ & $139(88.0)$ & $192(87.3)$ & \\
\hline $\begin{array}{c}(50.01-80.00 \%) \\
\text { Good }(>80.01 \%)\end{array}$ & $0(0.0)$ & $3(2.5)$ & $3(1.4)$ & \\
\hline Sedentary time (min) & $224.76 \pm 122.81$ & $234.53 \pm 148.85$ & $231.77 \pm 141.79$ & 0.647 \\
\hline Overall sleeping quality & $5.10 \pm 3.10$ & $6.06 \pm 3.56$ & $5.79 \pm 3.45$ & 0.063 \\
\hline Poor sleeper & $32(51.6)$ & $93(58.9)$ & $125(56.8)$ & \multirow{2}{*}{0.409} \\
\hline Good sleeper & $30(48.4)$ & $65(41.1)$ & $95(43.2)$ & \\
\hline Body weight (kg) & $57.83 \pm 7.06$ & $58.15 \pm 11.35$ & $58.06 \pm 10.31$ & 0.803 \\
\hline $\operatorname{BMI}\left(\mathrm{kg} / \mathrm{m}^{2}\right)$ & $23.88 \pm 2.77$ & $24.72 \pm 4.73$ & $24.48 \pm 4.28$ & 0.107 \\
\hline Underweight & $2(3.2)$ & $8(5.1)$ & $10(4.5)$ & \multirow{4}{*}{ - } \\
\hline Normal weight & $37(59.7)$ & $88(55.7)$ & $125(56.8)$ & \\
\hline Overweight & $23(37.1)$ & $46(29.1)$ & $69(31.4)$ & \\
\hline Obese & $0(0.0)$ & $16(10.1)$ & $16(7.3)$ & \\
\hline PBF (\%) & $34.74 \pm 4.19$ & $35.30 \pm 5.47$ & $35.14 \pm 5.13$ & 0.465 \\
\hline SMM (kg) & $14.98 \pm 2.17$ & $14.68 \pm 3.03$ & $14.77 \pm 2.81$ & 0.474 \\
\hline Low muscle mass $\left(\mathrm{kg} / \mathrm{m}^{2}\right)$ & $9(14.5)$ & $34(21.5)$ & $43(19.5)$ & \multirow{2}{*}{0.322} \\
\hline Adequate muscle mass $\left(\mathrm{kg} / \mathrm{m}^{2}\right)$ & $53(85.5)$ & $124(78.5)$ & $177(80.5)$ & \\
\hline \multicolumn{5}{|l|}{ Sarcopenia } \\
\hline Present & $0(0.0)$ & $27(17.1)$ & $27(12.3)$ & \multirow{2}{*}{$0.001^{* *}$} \\
\hline Absent & $62(100.0)$ & $131(82.9)$ & $193(87.7)$ & \\
\hline Serum vitamin $\mathrm{D}^{\mathrm{c}}(\mathrm{nmol} / \mathrm{L})$ & $36.46 \pm 13.87$ & $37.92 \pm 14.52$ & $37.51 \pm 14.32$ & 0.501 \\
\hline Deficiency $(<30 \mathrm{nmol} / \mathrm{L})$ & $23(37.7)$ & $48(30.8)$ & $71(32.7)$ & \multirow{3}{*}{0.419} \\
\hline Insufficiency (30-49 nmol/L) & $26(42.6)$ & $82(52.6)$ & $108(49.8)$ & \\
\hline Adequate $(\geq 50 \mathrm{nmol} / \mathrm{L})$ & $12(19.7)$ & $26(16.6)$ & $38(17.5)$ & \\
\hline CCI & $0.45 \pm 0.56$ & $0.60 \pm 0.73$ & $0.56 \pm 0.69$ & 0.107 \\
\hline
\end{tabular}

* Significant at $p<0.05$, two-tailed. ${ }^{* *}$ Significant at $p<0.01$, two-tailed. ${ }^{a}$ Based on 218 of respondents; ${ }^{\mathrm{b}}$ household/personal income range as per The Malaysian Economic Planning Unit (Prime Minister's Department, Economic Planning Unit, 2016) (Conversion rate, RM3.98 = USD 1 at the time of data collection.); ${ }^{c}$ based on 217 respondents. 


\subsection{Factors Contributing to the Risk of Frailty}

Table ?? demonstrates the result of a multinomial logistic regression model regarding the associations of frailty with its potential risk or protecting factors. Increased age $(\mathrm{OR}=1.155, \mathrm{CI}=1.059-1.259, p=0.001)$, sedentary behaviour $(\mathrm{OR}=1.004, \mathrm{CI}=1.001-1.008$, $p=0.013)$ and poor sleep quality $(\mathrm{OR}=1.262, \mathrm{CI}=1.085-1.469, p=0.003)$ were associated with increased risk of frailty, while age less than 65 years old $(\mathrm{OR}=0.134, \mathrm{CI}=0.028-0.639$, $p=0.012)$ and good sleep quality $(\mathrm{OR}=0.071, \mathrm{CI}=0.009-0.572, p=0.013)$ acted as protective factors. Multivariate logistic regression showed that year of education $(\mathrm{OR}=0.920$, $\mathrm{CI}=0.846-0.999, p=0.047)$, DQI $(\mathrm{OR}=1.045, \mathrm{CI}=1.004-1.087, p=0.030)$, $\mathrm{BMI}(\mathrm{OR}=1.269$, $\mathrm{CI}=1.042-1.547, p=0.018)$ and SMM $(\mathrm{OR}=0.750, \mathrm{CI}=0.578-0.971, p=0.029)$ contributed significantly to pre-frailty, while an increased DQI (OR $=1.112, \mathrm{CI}=1.025-1.207, p=0.011)$ was associated with an increased risk for frailty, and being a good sleeper (OR $=0.057$, $\mathrm{CI}=0.003-0.946, p=0.046)$ and having adequate muscle mass $(\mathrm{OR}=0.068, \mathrm{CI}=0.006-0.796$, $p=0.032$ ) were protective factors for frailty.

As depicted in Table 4, it is worth noting that risk factors for the components or criteria of frailty vary. While increased age (slow gait speed, $p<0.001$; weak grip strength, $p=0.002$ ), being 65 years old and above (slow gait speed, $p=0.010$; weak grip strength, $p=0.026$ ) and reduced years of education (slow gait speed, $p=0.008$; weak grip strength, $p=0.001$ ) increased the risk of slow gait speed and weak grip strength, respondents with a better dietary quality index were at risk of unintentional weight loss $(p=0.040)$. Respondents with increased CCI were associated with a higher risk of having slow gait speed (multivariableadjusted OR: 1.945, CI: 1.108-3.416, $p=0.021$ ). Compared with their counterparts with better sleep quality, respondents with poor sleep quality had a fivefold higher risk of slow gait speed (multivariable-adjusted OR: 5.406, 95\% CI: 1.807-16.172, $p=0.003$ ) and approximately threefold higher risk of self-reported exhaustion (multivariable-adjusted OR: 2.996, 95\% CI: 1.293-6.941, $p=0.010)$. An increased BMI was associated with a higher risk of weak grip strength $(p=0.028)$, while being underweight increased the risk of unintentional weight loss of the respondents by more than seven times (multivariable-adjusted OR: 7.562, 95\% CI: $1.199-47.714, p=0.031$ ). 
Table 3. Multinomial logistic regression between variables and frailty.

\begin{tabular}{|c|c|c|c|c|c|c|c|c|}
\hline \multirow{3}{*}{ Variables } & \multicolumn{4}{|c|}{ Univariate Logistic Regression } & \multicolumn{4}{|c|}{ Multivariate Logistic Regression } \\
\hline & \multicolumn{2}{|c|}{ Pre-Frailty } & \multicolumn{2}{|c|}{ Frailty } & \multicolumn{2}{|c|}{ Pre-Frailty } & \multicolumn{2}{|c|}{ Frailty } \\
\hline & Odds Ratio & CI & Odds Ratio & CI & Odds Ratio & CI & Odds Ratio & CI \\
\hline Age & NS & NS & $1.155^{* *}$ & $1.059-1.259$ & NS & NS & NS & NS \\
\hline$<65$ years old & NS & NS & $0.134 *$ & $0.028-0.639$ & NS & NS & NS & NS \\
\hline$\geq 65$ years old & 1 & & 1 & & 1 & & 1 & \\
\hline \multicolumn{9}{|l|}{$\bar{M}$ Marital status } \\
\hline Single/divorced & NS & NS & NS & NS & & & & \\
\hline Married & 1 & & 1 & & & & & \\
\hline Year of education & NS & NS & NS & NS & 0.920 * & $0.846-0.999$ & NS & NS \\
\hline CCI & NS & NS & NS & NS & NS & NS & NS & NS \\
\hline DQI & NS & NS & NS & NS & $1.045^{*}$ & $1.004-1.087$ & $1.112 *$ & $1.025-1.207$ \\
\hline $\begin{array}{l}\text { Sedentary } \\
\text { behaviour }\end{array}$ & NS & NS & $1.004 *$ & $1.001-1.008$ & NS & NS & NS & NS \\
\hline Sleep quality & NS & NS & $1.262^{* *}$ & $1.085-1.469$ & NS & NS & NS & NS \\
\hline Good sleeper & NS & NS & $0.071^{*}$ & $0.009-0.572$ & NS & NS & $0.057 *$ & $0.003-0.946$ \\
\hline Poor sleeper & 1 & & 1 & & 1 & & 1 & \\
\hline $\mathrm{BMI}$ & NS & NS & NS & NS & 1.269 * & $1.042-1.547$ & 1.272 & $0.866-1.868$ \\
\hline Low muscle mass & 1 & & 1 & & 1 & & 1 & \\
\hline $\begin{array}{l}\text { Adequate muscle } \\
\text { mass }\end{array}$ & NS & NS & $0.218^{*}$ & $0.065-0.735$ & NS & NS & $0.068^{*}$ & $0.006-0.796$ \\
\hline Serum vit D level & NS & NS & NS & NS & NS & NS & NS & NS \\
\hline Deficiency & 1 & & 1 & & 1 & & 1 & \\
\hline Insufficiency & NS & NS & NS & NS & NS & NS & NS & NS \\
\hline Adequate & NS & NS & NS & NS & NS & NS & NS & NS \\
\hline
\end{tabular}


Table 4. Univariate logistic regression between selected variables and components of frailty $(n=220)$.

\begin{tabular}{|c|c|c|c|c|c|}
\hline \multirow[b]{2}{*}{ Characteristics } & \multicolumn{5}{|c|}{ Frailty Components } \\
\hline & $\begin{array}{l}\text { Unintentional } \\
\text { Weight Loss }\end{array}$ & $\begin{array}{l}\text { Self-Reported } \\
\text { Exhausting }\end{array}$ & $\begin{array}{l}\text { Low Energy } \\
\text { Expenditure }\end{array}$ & Slow Gait Speed & Weak Grip Strength \\
\hline Age & NS & NS & NS & $\begin{array}{c}1.130 * * \\
(1.060-1.204)\end{array}$ & $\begin{array}{c}1.071 * * \\
(1.026-1.117)\end{array}$ \\
\hline$<65$ years old & 1 & 1 & 1 & 1 & 1 \\
\hline$\geq 65$ years old & NS & NS & NS & $\begin{array}{c}3.732 * \\
(1.362-10.227)\end{array}$ & $\begin{array}{c}1.852 * \\
(1.076-3.187)\end{array}$ \\
\hline Years of education & NS & NS & NS & $\begin{array}{c}0.885^{* *} \\
(0.809-0.969)\end{array}$ & $\begin{array}{c}0.904^{* *} \\
(0.851-0.961)\end{array}$ \\
\hline CCI & NS & NS & NS & $\begin{array}{c}1.945 * \\
(1.108-3.416)\end{array}$ & NS \\
\hline DQI & $\begin{array}{c}1.069 * \\
(1.003-1.139)\end{array}$ & NS & NS & NS & NS \\
\hline $\begin{array}{c}\text { Sedentary } \\
\text { behaviour (min) }\end{array}$ & NS & NS & NS & NS & NS \\
\hline Sleep quality & NS & NS & NS & $\begin{array}{c}1.181 \text { ** } \\
(1.061-1.314)\end{array}$ & NS \\
\hline Good sleeper & 1 & 1 & 1 & 1 & 1 \\
\hline Poor sleeper & NS & $\begin{array}{c}2.996 * \\
(1.293-6.941)\end{array}$ & NS & $\begin{array}{c}5.406^{* *} \\
(1.807-16.172)\end{array}$ & NS \\
\hline BMI & NS & NS & NS & NS & $\begin{array}{c}1.080 * \\
(1.008-1.156)\end{array}$ \\
\hline Underweight & $\begin{array}{c}7.562 * \\
(1.199-47.714)\end{array}$ & NS & NS & NS & NS \\
\hline $\begin{array}{c}\text { Normal weight } \\
\text { Overweight }\end{array}$ & 1 & 1 & 1 & 1 & 1 \\
\hline $\begin{array}{l}\text { Oberweignt } \\
\text { Obese }\end{array}$ & NS & NS & NS & NS & NS \\
\hline & NS & NS & NS & NS & - \\
\hline SMM & NS & NS & NS & NS & NS \\
\hline $\begin{array}{c}\text { Adequate muscle } \\
\text { mass }\end{array}$ & 1 & 1 & 1 & 1 & 1 \\
\hline Low muscle mass & NS & NS & NS & NS & NS \\
\hline Sarcopenia & & & & & \\
\hline Present & NS & NS & NS & NS & - \\
\hline Absent & 1 & 1 & 1 & 1 & \\
\hline PBF & NS & NS & NS & NS & NS \\
\hline Serum vit D level & NS & NS & NS & NS & NS \\
\hline Deficiency & NS & NS & NS & NS & NS \\
\hline Insufficiency & NS & NS & NS & NS & NS \\
\hline Adequate & 1 & 1 & 1 & 1 & 1 \\
\hline
\end{tabular}

\section{Discussion}

The prevalence of frailty found in this cohort of postmenopausal women was comparable to that observed in earlier studies in Europe [4], USA [9], Korea [5] and Japan [6] but lower than that noted in other studies in China [7] and Singapore [32]. On the other hand, the prevalence of frailty in this study was comparable to that observed by Badrasawi et al. [16] but lower than that noted in other local studies [8,14,15]. Two-thirds of the participants were pre-frail, which is a higher fraction than that of studies in Europe [4], Brazil [33], Korea [5] and Japan [6] but lower than that of a previous local study [8]. The discrepancies of the prevalence of frailty may be attributed to the different approaches 
used to diagnose frailty, the different target populations and settings and the sample size of the studies. The most commonly observed feature of weak handgrip strength among the respondents was supported by another study [34]. The prevalence of weak handgrip strength was comparable to that observed in several local studies [13,15], despite being higher than that in another study [35]. On the other hand, the most prevalent component reported in Europe [4], Brazil [33] and Korea [5] was self-reported exhaustion. The finding is not unexpected, as Asians have lower muscle mass or experience a more rapid decline in muscle strength and physical function, leading to weaker handgrip strength [36].

Several factors significantly contributed to pre-frailty, namely, year of education, DQI, BMI and SMM, while DQI, being a good sleeper and having adequate muscle mass significantly contributed to the assessment of frailty. Among the sociodemographic factors, age and being younger than 65 years old significantly contributed to the risk of frailty in the univariate model. The risk of frailty increased with age, which has been proven in other studies [7,35]. Increased age may lead to loss of muscle mass [37] and muscle strength, subsequently leading to a decrease in gait speed and handgrip strength [27], which supports the result of the present study that an increase in age is also associated with slow gait speed and weak handgrip strength.

It is worth noting that pre-frailty is prevalent among respondents below 65 years of age, which, without proper interventions, places them at increased risk of frailty as they age. Appropriate intervention and strategies should be formulated to delay the onset of frailty among these younger individuals. On the other hand, years of education, as well as its components, namely, gait speed and weak handgrip strength, was a protective factor for pre-frailty, which is in accordance with the results of da Alexandre et al. [38] and a recent study in Korea in which elderly people with lower education had poorer handgrip strength [39]. Higher education may act as a mediator that allows an individual to access a better healthcare system; promotes the adoption of healthy behaviours, such as healthy eating and being physically active; and lowers health risk behaviour, such as smoking and consuming alcohol [38], thereby attenuating the risk of frailty and its components. Previous local studies confirmed that individuals with a lower education level had 6.5 times the odds of experiencing unmet needs compared to more highly educated individuals [40] with a lower dietary quality [41]. We failed to find a significant association between age and the risk of frailty in the multivariate model. We do not have an explanation for this, but it could be attributed to factors such as body weight status and social factors, which masked the association of stronger predictors with the risk of frailty and, thus, led to stronger predictors being subsumed [42].

An interesting finding in the present study is that higher DQI increased the risk of pre-frailty and frailty, which is in contrast with the findings of other studies [43-45]. The possible explanation for the inconsistent findings may be attributed to different dietary profiles that could produce a similar score; for example, a DQI of 50 can be produced from several different dietary combinations [46]. In addition, the current dietary recommendation may be unable to fit into the daily dietary requirements of postmenopausal women [47]. Development or modification of the dietary recommendation for postmenopausal women should be considered in order to improve the health status of this population. In addition, the time frame of assessing the dietary pattern was for the past one month, which may not represent the respondents' habitual dietary patterns, or respondents may have alerted their habitual dietary patterns. Cohort or intervention studies would delineate the effect of dietary quality on the risk of frailty in future studies.

In terms of anthropometry indicators, the contribution of BMI to the risk of prefrailty was not unexpected. Higher BMI was consistently reported to increase the risk of frailty $[13,35,48]$, which may be attributed to the release of resistin by adipocytes due to excessive fat storage [49], resulting in activation of the inflammation process and immune system [50]. Reduced BMI and underweight have been proposed as risk factors for frailty [51], but they were absent in the present study. The relationship between BMI and risk of frailty was proposed to have a U-shaped curve, as either being underweight or 
overweight increased the risk of frailty [51]. BMI is a surrogate measure of body weight status but fails to reflect body composition (to differentiate between fat mass and fat-free mass). Thus, the measurement of fat mass and muscle mass should be considered when assessing the relationship between BMI and risk of frailty in future studies.

Reduced SMM contributed to a higher risk of pre-frailty and having adequate muscle mass was a protective factor for frailty, echoing the results of recent studies $[5,8]$, wherein a reduction of five units $\mathrm{n}$ muscle density was associated with a $20 \%$ increase in the risk of frailty. The decrease in SMM may be accompanied by a loss of muscle strength [27], affecting the individual's handgrip strength and walking speed. However, as frailty and sarcopenia overlap each other [27] and the potential mediating effect of sarcopenia on the outcome of frailty [52], it is difficult to delineate the actual relationship between sarcopenia and the risk of frailty. More extensive work is warranted to explore the potential relationship. The relationship between 25(OH)D and frailty had long been evident. Recent studies showed that a sufficient level of $25(\mathrm{OH}) \mathrm{D}$ is a protective factor for frailty among the older population $[5,53,54]$. However, the present study failed to demonstrate the relationship between vitamin $\mathrm{D}$ and frailty. The possible mechanism is that $25(\mathrm{OH}) \mathrm{D}$ receptors were present in several organs and tissues, including muscle tissue. Thus, decreasing age will lead to the deterioration of muscle strength [55]. Discrepancies were observed to exist in another study [56], and, as such, it remains unclear as to whether $25(\mathrm{OH}) \mathrm{D}$ is among the factors that cause the development of a frailty phenotype or the consequences of frailty [55]. In short, the relationship between $25(\mathrm{OH}) \mathrm{D}$ and the risk of frailty in the present study should be interpreted with caution, as the present study had a small number of respondents with frailty, thus possibly affecting the statistical significance of the relationship.

Being a good sleeper reduced the risk of frailty, which is supported by a recent metaanalysis [57]. It was suggested that poor sleep quality is associated with a high level of inflammatory adipokines [57], which could lead to a catabolic process and the development of sarcopenia [58], thus increasing the risk of frailty. In the present study, poor sleep quality and poor sleepers were both associated with slow gait speed, one of the diagnostic criteria for both sarcopenia and frailty, and this result is in accordance with that of Ershley [58], suggesting the possible influence of poor sleep quality on a higher risk of frailty.

Several limitations should be considered in the present study. Firstly, the present study was a cross-sectional study, making it difficult to determine the cause-effect relationship between factors and the risk of frailty. Secondly, the population involved in the present study were only Chinese postmenopausal women. Thus, it may not be possible to generalise this result to other populations. Thirdly, the diagnostic criteria for frailty were developed based on the Western population, which might be inappropriate for Asians. More prospective cohort studies are needed to delineate the determinants of frailty, and different populations should be assessed to enable the result to be generalised. The development of a cut-off value for the Asian population in diagnosing frailty is recommended.

\section{Conclusions}

In conclusion, approximately two in three postmenopausal women were pre-frail, while $7 \%$ were frail, with weak handgrip strength as the most common presenting feature. The present study also revealed that risk of frailty might present as early as middle age, as one out of three postmenopausal women presented with at least one frailty component. Several proposed variables significantly contributed to pre-frailty, namely, year of education, DQI, BMI and SMM, while DQI, good sleeper and adequate muscle mass significantly contributed to the assessment of frailty. The present study emphasises the importance of body weight and body composition management among postmenopausal women, as increased BMI and low SMM could contribute to the risk of frailty. The importance of good sleep quality in reducing the risk of frailty is also highlighted. In light of the expected health and social impacts of frailty on individuals and nations, more work is needed to improve the intervention planning and policy development related to frailty, especially among younger populations. 
Author Contributions: Conceptualisation, Y.M.C., Y.S.C. and Z.M.S.; methodology, K.S.C., Y.M.C., Y.S.C. and Z.M.S.; validation, K.S.C.; formal analysis, K.S.C.; investigation, K.S.C., Y.M.C., Y.S.C. and Z.M.S.; resources, K.S.C., Y.M.C., Y.S.C. and Z.M.S.; data curation, Y.M.C.; writing-original draft preparation, K.S.C.; writing-review and editing, K.S.C., Y.M.C., Y.S.C. and Z.M.S.; visualisation, K.S.C. and Y.M.C.; supervision, Y.M.C., Y.S.C. and Z.M.S.; project administration, K.S.C. and Y.M.C.; funding acquisition, Y.M.C. All authors have read and agreed to the published version of the manuscript.

Funding: This research was funded by the Ministry of Education Malaysia (Fundamental Research Grant Scheme Grant No. 5524844) and Universiti Putra Malaysia (Putra Grant IPS 9507400).

Institutional Review Board Statement: The study was conducted according to the guidelines of the Declaration of Helsinki, and approved by the Ethics Committee for Research Involving Human Subjects of Universiti Putra Malaysia (protocol code 2018-056 and date of approval: 31 May 2018).

Informed Consent Statement: Informed consent was obtained from all subjects involved in the study.

Data Availability Statement: Data is contained within the article or supplementary material.

Acknowledgments: We would like to express our gratitude to the respondents and enumerators for their excellent cooperation during the data collection process.

Conflicts of Interest: The authors declare no conflict of interest.

\section{References}

1. United Nations. Department of Economic and Social Affairs, Population Division. In World Population Prospects: The 2017 Revision; World Population Prospects: New York, NY, USA, 2021; Volume II, Demographic Profiles. [CrossRef]

2. Department of Statistics Malaysia. Selected Demographic Indicators Malaysia, 2019; Population \& Demography, Department of Statistics Malaysia: Putrajaya, Malaysia, 2019.

3. Department of Statistics Malaysia. Population Projection (Revised), Malaysia, 2010-2040; Population \& Demography, Department of Statistics Malaysia: Putrajaya, Malaysia, 2019.

4. Manfredi, G.; Midão, L.; Paúl, C.; Cena, C.; Duarte, M.; Costa, E. Prevalence of frailty status among the European elderly population: Findings from the Survey of Health, Aging and Retirement in Europe. Geriatr. Gerontol. Int. 2019, 19, 723-729. [CrossRef] [PubMed]

5. Jung, H.; Kim, M.; Lee, Y.; Won, C.W. Prevalence of physical Frailty and its multidimensional risk factors in Korean communitydwelling older adults: Findings from Korean frailty and aging cohort study. Int. J. Environ. Res. Public Health 2020, 17, 7883. [CrossRef] [PubMed]

6. Murayama, H.; Kobayashi, E.; Okamoto, S.; Fukaya, T.; Ishizaki, T.; Liang, J.; Shinkai, S. National prevalence of frailty in the older Japanese population: Findings from a nationally representative survey. Arch. Gerontol. Geriatr. 2020, 91, 104220. [CrossRef] [PubMed]

7. Woo, J.; Zheng, Z.; Leung, J.; Chan, P. Prevalence of Frailty and contributory factors in three Chinese populations with different socioeconomic and healthcare characteristics. BMC Geriatr. 2015, 15, 163. [CrossRef]

8. Norazman, C.W.; Adznam, S.N.; Jamaluddin, R. Physical frailty among urban-living community-dwelling older adults in Malaysia. Int. J. Environ. Res. Public Health 2020, 17, 6549. [CrossRef] [PubMed]

9. Fried, L.P.; Tangen, C.M.; Walston, J.; Newman, A.B.; Hirsch, C.; Gottdiener, J.; Seeman, T.; Tracy, R.; Kop, W.J.; Burke, G.; et al. Frailty in Older Adults: Evidence for a Phenotype. J. Gerontol. Med. Sci. Am. 2001, 56, 146-156. [CrossRef] [PubMed]

10. Goldfarb, M.; Bendayan, M.; Rudski, L.G.; Morin, J.F.; Langlois, Y.; Ma, F.; Lachapelle, K.; Cecere, R.; DeVarenes, B.; Tchervenkov, C.I.; et al. Cost of Cardiac Surgery in Frail Compared with Nonfrail Older Adults. Can. J. Cardiol. 2017, 33, 1020-1026. [CrossRef]

11. Veronese, N.; Cereda, E.; Stubbs, B.; Solmi, M.; Luchini, C.; Manzato, E.; Sergi, G.; Manu, P.; Harris, T.; Luig, F.; et al. Risk of cardiovascular disease morbidity and mortality in frail and pre-frail older adults: Results from a meta-analysis and exploratory meta-regression analysis. Ageing Res. Rev. 2017, 35, 63-73. [CrossRef]

12. Sathasivam, J.; Kamaruzzaman, S.B.; Hairi, F.; Ng, C.W.; Chinna, K. Frail Elders in an Urban District Setting in Malaysia. Asia-Pac. J. Public Health 2015, 27 (Suppl. 8), 52S-61S. [CrossRef]

13. Badrasawi, M.; Shahar, S.; Kaur Ajit Singh, D. Risk Factors of Frailty Among Multi-Ethnic Malaysian Older Adults. Int. J. Gerontol. 2017, 11, 154-160. [CrossRef]

14. Nurzetty Sofia, Z.; Hazrin Husin, M.; Hidayah Ahmad, N.; Wong, Y.H.; Han, W.C.; Suzana, S.; Ismail, M.; Devinder Kaur, A.S. Association between Nutritional Status, Food Insecurity and Frailty among Elderly with Low Income. J. Sains Kesihat. Malays. 2017, 15, 51-59. [CrossRef]

15. Fairus Asma, M.H.; Siti Nur Asyura, A.; Zuriati, I.; Chan, Y.M.; Nur Hafizah, A.A. Prevalence of frailty syndrome and its associated factors among community-dwelling elderly in East Coast of Peninsular Malaysia. SAGE Open Med. 2018, 6, 2050312118775581. [CrossRef] 
16. Rockwood, K.; Song, X.; Mitnitski, A. Changes in relative fitness and frailty across the adult lifespan: Evidence from the Canadian National Population Health Survey. Can. Med. Assoc. J. 2011, 183, E487-E494. [CrossRef]

17. Gill, T.M.; Gahbauer, E.A.; Allore, H.G.; Han, L. Transitions Between Frailty States Among Community-Living Older Persons. Arch. Intern. Med. 2006, 166, 418. [CrossRef] [PubMed]

18. Boey, K.W. Cross-validation of a short form of the CES-D in Chinese elderly. Int. J. Geriatr. Psychiatry 1999, 14, 608-617. [CrossRef]

19. Armstrong, T.; Bull, F. Development of the World Health Organization Global Physical Activity Questionnaire (GPAQ). J. Public Health 2006, 14, 66-70. [CrossRef]

20. The Economic Planning Unit. Tenth Malaysia Plan 2011-2015; The Economic Planning Unit: Putrajaya, Malaysia, 2010.

21. Lee, T.T.; Norimah, A.K.; Safiah, M.Y. B17. Development of Healthy Eating Index (HEI) for Malaysian adults. In Proceedings of the 26th Scientific Conference and Annual General Meeting of the Nutrition Society of Malaysia, Nutrition Society of Malaysia, Kuala Lumpur, Malaysia, 24-25 March 2011. Available online: http:/ /www.nutriweb.org.my/downloads/NSM\%2026\%20Conference\% 20Prog\%20\&\%20Abstr\%20Book.pdf (accessed on 2 March 2018).

22. Institute for Public Health. National Health and Morbidity Survey (NHMS) 2015; Institute for Public Health, Ministry of Health Malaysia: Kuala Lumpur, Malaysia, 2015; Volume 1.

23. Ministry of Health Malaysia. Malaysian Dietary Guidelines 2010; National Coordinating Committee on Food and Nutrition, Ministry of Health Malaysia: Putrajaya, Malaysia, 2010.

24. Buysse, D.J.; Reynolds, C.F.; Monk, T.H.; Berman, S.R.; Kupfer, D.J. The Pittsburgh Sleep Quality Index: A new instrument for psychiatric practice and research. Psychiatry Res. 1989, 28, 193-213. [CrossRef]

25. World Health Organization. Obesity: Preventing and Managing the Global Epidemic — Report of a WHO Consultation; World Health Organization: Geneva, Switzerland, 2000.

26. Lee, R.C.; Wang, Z.; Heo, M.; Ross, R.; Janssen, I.; Heymsfield, S.B. Total-body skeletal muscle mass: Development and cross-validation of anthropometric prediction models. Am. J. Clin. Nutr. 2000, 72, 796-803. [CrossRef] [PubMed]

27. Cruz-Jentoft, A.J.; Baeyens, J.P.; Bauer, J.M.; Boirie, Y.; Cederholm, T.; Landi, F.; Martin, F.C.; Michel, J.P.; Rolland, Y.; Schneider, S.M.; et al. Sarcopenia: European consensus on definition and diagnosis: Report of the European Working Group on Sarcopenia in Older People. Age Ageing 2010, 39, 412-423. [CrossRef]

28. Institute of Medicine. Food and Nutrition Board. Dietary Reference Intakes for Calcium and Vitamin D; Institute of Medicine: Washington, DC, USA, 2010.

29. Charlson, M.E.; Charlson, R.E.; Peterson, J.C.; Marinopoulos, S.S.; Briggs, W.M.; Hollenberg, J.P. The Charlson comorbidity index is adapted to predict costs of chronic disease in primary care patients. J. Clin. Epidemiol. 2008, 61, 1234-1240. [CrossRef] [PubMed]

30. Ondeck, N.T.; Bovonratwet, P.; Ibe, I.K.; Bohl, D.D.; McLynn, R.P.; Cui, J.J.; Baumgaertner, M.R.; Grauer, J.N. Discriminative ability for adverse outcomes after surgical Management of hip Fractures: A comparison of the Charlson comorbidity index, Elixhauser comorbidity measure, and modified frailty index. J. Orthop. Trauma 2018, 32, 231-237. [CrossRef] [PubMed]

31. Sperandei, S. Understanding logistic regression analysis. Biochem. Med. 2014, 24, 12-20. [CrossRef]

32. Wang, X.; Lu, Y.; Li, C.; Larbi, A.; Feng, L.; Shen, Q.; Chong, M.S.; Lim, W.S.; Feng, L. Associations of lifestyle activities and a heathy diet with frailty in old age: A community-based study in Singapore. Aging 2020, 12, 288-308. [CrossRef]

33. Melo, R.C.; Cipolli, G.C.; Buarque, G.L.A.; Yassuda, M.S.; Cesari, M.; Oude Voshaar, R.C.; Aprahamian, I. Prevalence of Frailty in Brazilian Older Adults: A Systematic Review and Meta-Analysis. J. Nutr. Health Aging 2020, 24, 708-716. [CrossRef] [PubMed]

34. Xue, Q.L. The Frailty Syndrome: Definition and Natural History. Clin. Geriatr. Med. 2011, 27, 1-15. [CrossRef] [PubMed]

35. García-Peña, C.; Ávila-Funes, J.A.; Dent, E.; Gutiérrez-Robledo, L.; Pérez-Zepeda, M. Frailty prevalence and associated factors in the Mexican health and aging study: A comparison of the frailty index and the phenotype. Exp. Gerontol. 2016, 79, 55-60. [CrossRef] [PubMed]

36. Wu, Y.H.; Hwang, A.C.; Liu, L.K.; Peng, L.N.; Chen, L.K. Sex differences of Sarcopenia in Asian populations: The implications in diagnosis and management. J. Clin. Gerontol. Geriatr. 2016, 7, 37-43. [CrossRef]

37. Fried, L.P.; Walston, J. Frailty and failure to thrive. In Principles of Geriatric Medicine and Gerontology, 4th ed.; Hazzard, W.R., Blass, J.P., Ettinger, W.H., Jr., Halter, J.B., Ouslander, J., Eds.; McGraw Hill: New York, NY, USA, 1998.

38. Alexandre, T.d.S.; Corona, L.P.; Nunes, D.P.; Santos, J.L.F.; Duarte, Y.A.O.; Lebrão, M.L. Similarities among Factors Associated with Components of Frailty in Elderly: SABE Study. J. Aging Health 2014, 26, 441-457. [CrossRef]

39. Kim, C.R.; Jeon, Y.J.; Jeong, T. Risk factors associated with low handgrip strength in the older Korean population. PLoS ONE 2019, 14, e0214612. [CrossRef] [PubMed]

40. Lim, K.K.; Sivasampu, S.; Mahmud, F. Equity in access to health care in a rural population in Malaysia: A cross-sectional study. Aust. J. Rural Health 2017, 25, 102-109. [CrossRef] [PubMed]

41. Nohan, A.F.; Adznam, S.N.A.; Jamaluddin, R.; Norazman, C.W. Diet quality and its associated factors among community dwelling older adults in urban district in Kuala Lumpur, Malaysia. J. Med. Health Sci. 2020, 16 (Suppl. 6), 153-162.

42. Ding, J.; Kuha, M.; Murphy, Y.Y. Multidimensional predictors of physical frailty in older people: Identifying how and for whom they exert their effects. Biogerontology 2017, 18, 237-252. [CrossRef] [PubMed]

43. Chan, R.; Leung, J.; Woo, J. Dietary patterns and risk of Frailty in Chinese community-dwelling older people in Hong Kong: A prospective cohort study. Nutrients 2015, 7, 7070-7084. [CrossRef] 
44. Jayanama, K.; Theou, O.; Godin, J.; Cahill, L.; Shivappa, N.; Hébert, J.R.; Wirth, M.D.; Park, Y.M.; Fung, T.T.; Rockwood, K. Relationship between diet quality scores and the risk of frailty and mortality in adults across a wide age spectrum. BMC Med. 2021, 19, 64. [CrossRef] [PubMed]

45. Ward, R.E.; Orkaby, A.R.; Chen, J.; Hshieh, T.T.; Driver, J.A.; Gaziano, J.M.; Djousse, L. Association between Diet Quality and Frailty Prevalence in the Physicians' Health Study. J. Am. Geriatr. Soc. 2020, 68, 770-776. [CrossRef]

46. Nicklas, T.A.; O’Neil, C.E.; Fulgoni, V.L. Diet Quality Is Inversely Related to Cardiovascular Risk Factors in Adults. J. Nutr. 2012, 142, 2112-2118. [CrossRef] [PubMed]

47. Hengeveld, L.M.; Wijnhoven, H.A.; Olthof, M.R.; Brouwer, I.A.; Harris, T.B.; Kritchevsky, S.B.; Newman, A.B.; Visser, M. Prospective associations of poor diet quality with long-term incidence of protein-energy malnutrition in community-dwelling older adults: The Health, Aging, and Body Composition (Health ABC) Study. Am. J. Clin. Nutr. 2018, 107, 155-164. [CrossRef]

48. Boutin, E.; Natella, P.A.; Schott, A.M.; Bastuji-Garin, S.; David, J.P.; Paillaud, E.; Rolland, Y.; Canouï-Poitrine, F. Interrelations between body mass index, frailty, and clinical adverse events in older community-dwelling women: The EPIDOS cohort study. Clin. Nutr. 2017, 37, 1638-1644. [CrossRef] [PubMed]

49. Charansonney, O.L. Physical activity and aging: A life-long story. Discov. Med. 2011, 12, 177-185. Available online: http: / / www.ncbi.nlm.nih.gov/pubmed/21955845 (accessed on 26 June 2021). [PubMed]

50. Kunnari, A.; Ukkola, O.; Päivänsalo, M.; Kesäniemi, Y.A. High plasma resistin level is associated with enhanced highly sensitive C-reactive protein and leukocytes. J. Clin. Endocrinol. Metab. 2006, 91, 2755-2760. [CrossRef] [PubMed]

51. Hubbard, R.E.; Lang, I.A.; Llewellyn, D.J.; Rockwood, K. Frailty, body mass index, and abdominal obesity in older people. J. Gerontol. A Biol. Sci. Med. Sci. 2010, 65, 377-381. [CrossRef] [PubMed]

52. Marzetti, E.; Calvani, R.; Bernabei, R.; Leeuwenburgh, C. Apoptosis in Skeletal Myocytes: A Potential Target for Interventions against Sarcopenia and Physical Frailty-A Mini-Review. Gerontology 2012, 58, 99-106. [CrossRef] [PubMed]

53. Buchebner, D.; Bartosch, P.; Malmgren, L.; McGuigan, F.E.; Gerdhem, P.; Akesson, K.E. Association between Vitamin D, Frailty, and Progression of Frailty in Community-Dwelling Older Women. J. Clin. Endocrinol. Metab. 2019, 104, 6139-6147. [CrossRef] [PubMed]

54. Vaes, A.M.M.; Brouwer-Brolsma, E.M.; Toussaint, N.; de Regt, M.; Tieland, M.; van Loon, L.J.C.; de Groot, L.C.P.G.M. The association between 25-hydroxyvitamin D concentration, physical performance and frailty status in older adults. Eur. J. Nutr. 2019, 58, 1173-1181. [CrossRef] [PubMed]

55. Marcos-Pérez, D.; Sánchez-Flores, M.; Proietti, S.; Bonassi, S.; Costa, S.; Teixeira, J.P.; Fernández-Tajes, J.; Pásaro, E.; Valdiglesias, V.; Laffon, B. Low vitamin D levels and frailty status in older adults: A systematic review and meta-analysis. Nutrients 2020, 12, 2286. [CrossRef] [PubMed]

56. Schöttker, B.; Saum, K.U.; Perna, L.; Ordóñez-Mena, J.M.; Holleczek, B.; Brenner, H. Is vitamin D deficiency a cause of increased morbidity and mortality at older age or simply an indicator of poor health? Eur. J. Epidemiol. 2014, 29, 199-210. [CrossRef] [PubMed]

57. Pourmotabbed, A.; Boozari, B.; Babaei, A.; Asbaghi, O.; Campbell, M.S.; Mohammadi, H.; Hadi, A.; Moradi, S. Sleep and frailty risk: A systematic review and meta-analysis. Sleep Breath 2020, 24, 1187-1197. [CrossRef] [PubMed]

58. Ershler, W.B. A gripping reality: Oxidative stress, inflammation, and the pathway to frailty. J. Appl. Physiol. 2007, 103, 3-5. [CrossRef] [PubMed] 